"This is the peer reviewed version of the following article: Chem. Eur. J. 2016, 22 (38), 13496 , which has been published in final form at [10.1002/chem.201601690]. This article may be used for non-commercial purposes in accordance with Wiley Terms and Conditions for Self-Archiving."

\title{
Molecular basis for the recognition of higher fullerenes into ureidopyrimidinone-cyclotriveratrylene self-assembled capsules
}

\author{
Elisa Huerta, ${ }^{[a]}$ Stefano Artin Serapian, ${ }^{[a]}$ Eva Santos, ${ }^{[a]}$ Enrique Cequier, ${ }^{[a]}$ Carles Bo, ${ }^{[a]}$ and Javier de \\ Mendoza*[a]
}

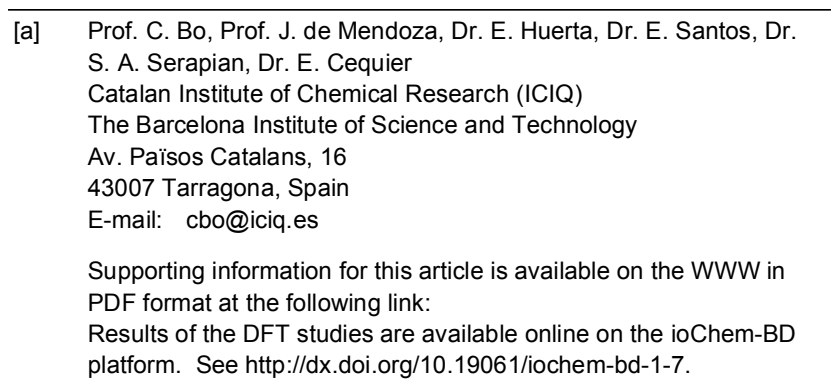

\begin{abstract}
Fullerenes $\mathrm{C}_{60}, \mathrm{C}_{70}$, and $\mathrm{C}_{84}$ may be readily encaged within a hydrogen-bonded dimeric capsule, based on two concave cyclotriveratrylene (CTV) scaffolds each bearing three self-complementary 2-ureido-4-[1H]-pyrimidinone (UPy) subunits. We herein report NMR and CD studies-complemented by dispersion-corrected density functional theory calculations-aiming to characterize such capsulefullerene complexes both structurally and energetically. Six fullerenes are considered: in agreement with experiment, calculations find that encapsulation is most favorable for $\mathrm{C}_{84}$ (on a par with $\mathrm{C}_{90}$ ), and follows the trend $\mathrm{C}_{60}<\mathrm{C}_{70}<\mathrm{C}_{76}<\mathrm{C}_{78}<\mathrm{C}_{84} \approx \mathrm{C}_{90}$. As also found by NMR, the most stable capsules are formed by monomers of identical stereochemistry; with UPy and the CTV's OMe groups in mutual anti orientation; and UPy-CTV ethylene linkers within the capsular surface plane. Up to $\mathrm{C}_{78}$, encapsulation is favored by increasing host-guest contacts, but the trend is thereafter increasingly inhibited by growing capsule strain.
\end{abstract}

\section{Introduction}

Despite the widespread interest in fullerenes ${ }^{[1]}$ and endohedral fullerenes, ${ }^{[2]}$ the chemistry and properties of higher members of this family of carbon allotropes (known as 'higher fullerenes'; $>\mathrm{C}_{70}$ ) remains mostly unexplored, mainly due to their low abundance, poor solubility and difficult separation. To date, the most efficient method to purify higher fullerenes is by multiple runs of recycling HPLC. ${ }^{[3]}$ Most of the alternative methods for fullerene separation and purification (i.e by sublimation, ${ }^{[4]}$ reversible chemical reactions, ${ }^{[5]}$ selective complexation with Lewis acids, ${ }^{[6]}$ or host-guest chemistry ${ }^{[7]}$ are only selective towards the major component $\mathrm{C}_{60}$; examples in literature where $C_{70}$ or higher fullerenes are preferred are scarce. ${ }^{[8]}$ Although preferential precipitation of $C_{70}$ over $C_{60}$ has indeed been reported with $p$-halohomooxacalix[3]arenes, subsequent release of the fullerene and retrieval of the valuable host proved difficult due to the complex's high stability. ${ }^{[9]}$

In the case of higher fullerenes, some successful and elegant examples have been described over the past decade. ${ }^{[0]}$ For example, Fukazawa et al. ${ }^{[11]}$ have employed a double calix[5]arene container to extract $\mathrm{C}_{94}$ and $\mathrm{C}_{96}$ from fullerene mixtures in an elegant way. At temperatures above $100^{\circ} \mathrm{C}$, the container undergoes a syn-anti isomerization (from the $\mathrm{C}$-shaped conformer to its S-shaped counterpart), causing the trapped fullerenes to be released. In another approach by Aida et al., ${ }^{[12]}$ macrocyclic zinc 
porphyrin dimers were employed for direct extraction of $\geq \mathrm{C}_{76}$ species from fullerene mixtures: after repeated extractions, this allowed enrichment with the rare fullerenes $C_{102}-C_{110}$. Recently, the same group reported the enantioselective extraction of the chiral fullerene $\mathrm{C}_{76}\left(7 \%\right.$ e.e.) from a racemic mixture, using an asymmetrically distorted porphyrin dimer. ${ }^{[13]}$ Despite the inherent elegance of these processes, all of them require chromatography at some stage.
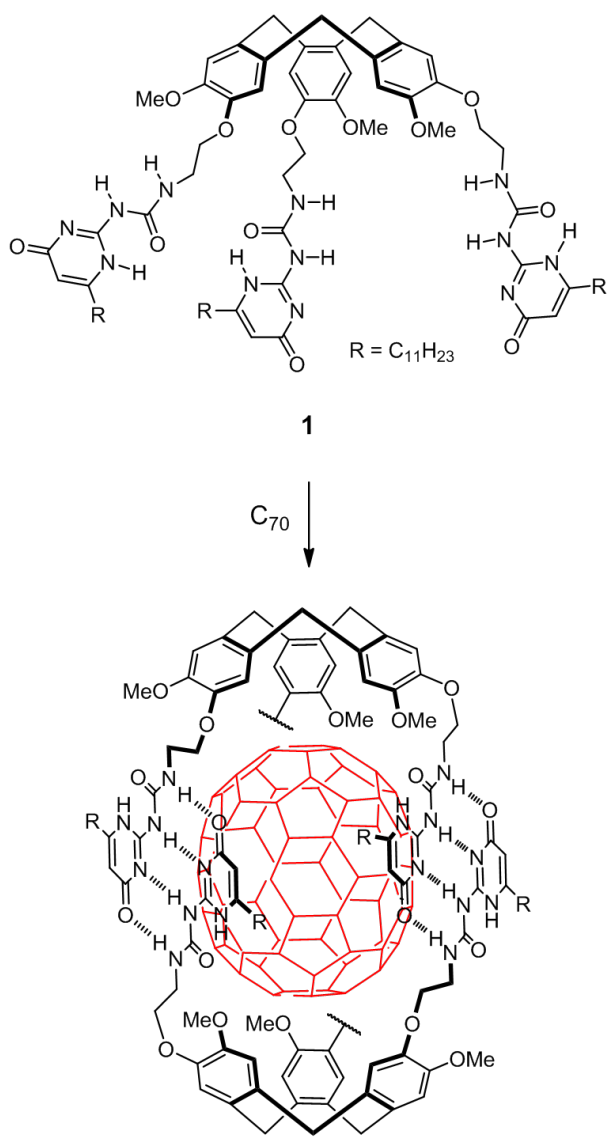

$\mathrm{C}_{70} @ \mathbf{1}_{\mathbf{2}}$

Scheme 1. Structural formula of the capsule monomer $\mathbf{1}$ (top); and the hydrogen-bonded homochiral capsule $\mathbf{1}_{\mathbf{2}}$ with a $\mathrm{C}_{70}$ guest (red; bottom). In the latter structure, one of the three UPy dimers is omitted for clarity.

We have previously conceived and synthesized a hydrogen-bonded, self-assembled dimeric capsule $\mathbf{1}_{\mathbf{2}}$ that readily encapsulates fullerenes such as $\mathrm{C}_{60}, \mathrm{C}_{70},{ }^{[14]}$ and $\mathrm{C}_{84}{ }^{[15]}$ (Scheme 1 ). Each monomer $\mathbf{1}$ is constituted by a modified concave cyclotriveratrylene (CTV) platform, known for its complementarity to the convex surface of $\mathrm{C}_{60 .}{ }^{[16]}$ This CTV is endowed with three short chains bearing 2-ureido-4-[1H]-pyrimidinone (UPy) moieties: ${ }^{[17]}$ each of these can achieve dimerization with a UPy moiety belonging to another monomer 1 through a robust quadruple array of hydrogen bonds (Scheme 1 and Fig. 1 ), providing a total of 12 favorable hydrogen bonds in the resulting dimer $\mathbf{1}_{\mathbf{2}}$. Single solid-liquid extractions of crude fullerene mixtures (fullerite) with solutions of the capsule in tetrahydrofuran (THF) promote selective encapsulation of fullerenes, which can then be easily separated from the remaining fullerenes by filtration. Subsequent addition of some trifluoroacetic acid to the solution breaks the hydrogen bonds, rupturing the capsules and allowing encapsulated guests to precipitate. Recycling of the host is simply achieved by evaporation. Remarkably, no chromatography or tedious separation procedures are thus necessary with this method.

We herein present a detailed computational study, featuring dispersion-corrected ${ }^{[18]}$ density functional theory (DFT), with the aim of uncovering those energetic and structural factors that, at a molecular level, govern the formation of the most stable host-guest complexes. Our in silico results are crucially supported by experimental data.

Indeed, on top of accurately reproducing experimentally observed capsule selectivity towards fullerenes (preference for $\mathrm{C}_{84}$ over $\mathrm{C}_{70}$, and even more over $\mathrm{C}_{60}$ ), ${ }^{[14-15]}$ our calculations are also able to correctly predict the preferred structural conformation of the 
$\mathbf{1}_{\mathbf{2}}$ capsules as detected by NMR. Selectivity trends found by our calculations and previous experiments are here furthermore reconfirmed by racemization studies featuring $C D$ spectroscopy.

We structure our discussion as follows: we begin by outlining the NMR characterization of the various capsule conformers and tautomers, also discussing some key structural features of the capsules. We subsequently present the outcome of our DFT calculations, whereby energetic and structural implications of capsule-fullerene complex formation are analysed in detail, and in relation to six fullerene sizes $\left(\mathrm{C}_{60}, \mathrm{C}_{70}, \mathrm{C}_{76}, \mathrm{C}_{78}, \mathrm{C}_{84}\right.$, and $\left.\mathrm{C}_{90}\right)$ and several $\mathbf{1}_{\mathbf{2}}$ conformers. In the closing part of the discussion, we report our racemization study based on CD spectroscopy. We finally provide our conclusions.

\section{Results and Discussion}

\section{NMR Characterization}

Before proceeding with the theoretical study, a number of structural aspects of the fullerene@1 $\mathbf{1}_{2}$ complexes had to be verified by ${ }^{1} \mathrm{H}$ NMR, to help pinpoint their experimentally preferred conformations. These structural aspects and their assessment by NMR are discussed in the following subsections; related methodological details are reported as Supporting Information.

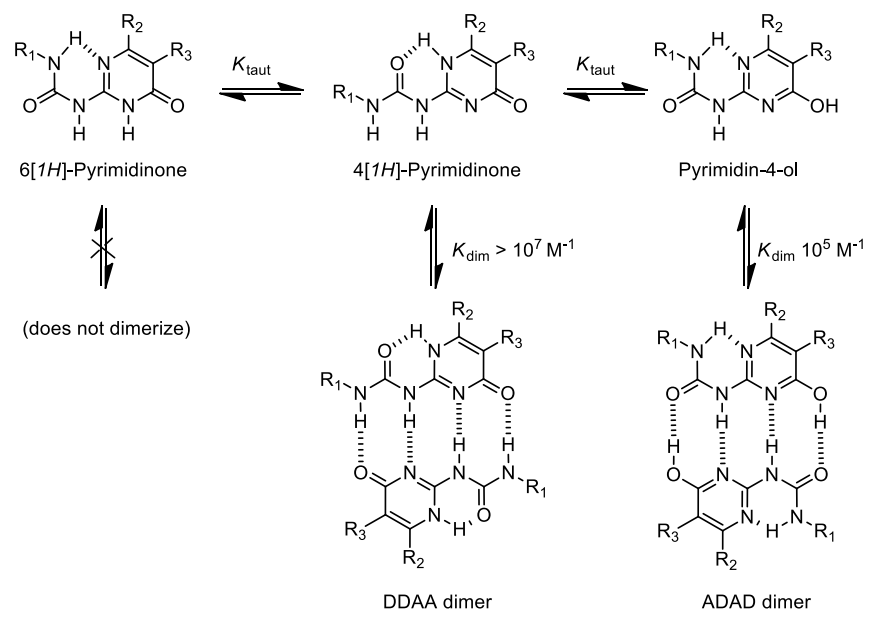

Figure 1. Tautomers and dimers formed by 2-ureidopyrimidinone moieties.

Tautomerism: In solution, ureidopyrimidinones exist in a tautomeric equilibrium (Fig. 1), but only the 4[1H]-pyrimidinone and the pyrimidyl-4-ol tautomers are able to self-assemble as dimers in apolar solvents; the former is usually the more stable of the two, since it contains a particularly favorable quadruple sequence DDAA of hydrogen bond donors (D) and acceptors (A). ${ }^{[17]}$ Experimentally, structure $\mathbf{1}_{\mathbf{2}}$ displayed the classical NMR pattern of the $4[1 \mathrm{H}]$-pyrimidinone tautomer (NH signals at $12.77,12.03$, and $10.66 \mathrm{ppm}$, see Fig. S3 in Supporting Information), whereas no signals for pyrimidin-4-ol dimers were observed; ${ }^{[19]}$ we therefore only considered the $4[1 H]$-pyrimidinone DDAA tautomer in our calculations.

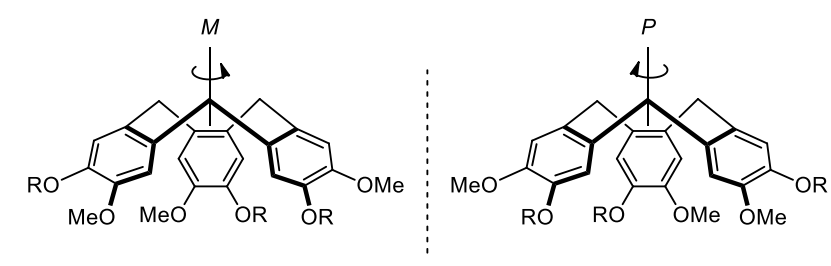

Figure 2. The two enantiomeric forms of chiral cyclotriveratrylene (CTV). 
Chirality: CTV scaffolds containing three OMe and three OR groups are chiral ${ }^{[20]}$ due to their bowl shaped architecture and their slow inversion (Fig. 2) ): if the CTV dome is oriented upwards and the UPy groups point downwards, $M$ chirality arises when the UPyO-(aromatic ring)-OMe sequence is encountered in the counterclockwise direction; $P$ chirality when it is encountered clockwise. Consequently, self-assembled capsules $\mathbf{1}_{\mathbf{2}}$ may either be homochiral (i.e. formed by a racemic pair of $M-M$ monomers or $P$ - $P$ monomers), or meso (achiral, where one of the monomers is $M$, and the other is $P$ ).

The prevalence of homochiral over achiral (meso) capsules was demonstrated experimentally by ${ }^{1} \mathrm{H}$ NMR. Initially, compound 1 was resolved into its two enantiomers by semi-preparative chiral HPLC in dichloromethane/methanol 9:1 (+0.1\% TFA). Once isolated, the CD spectra of the two major peaks in the HPLC chromatogram (named arbitrarily fraction I and fraction II, see Fig. S1 in Supporting Information) showed mirror images, clearly indicating that they correspond to the two enantiomeric species (Supporting Information, Fig. S2). Then, after adding 0.5 equivalents of $\mathrm{C}_{70}$ to ensure capsule formation, ${ }^{1} \mathrm{H}-\mathrm{NMR}$ spectra were recorded: of the racemic mixture; of each of the pure enantiomers; and of a 1:1 mixture of the two.

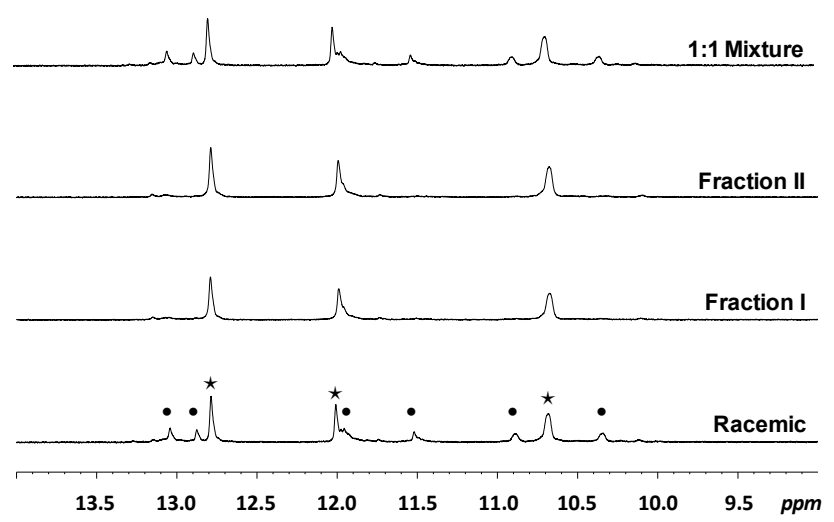

Figure 3. ${ }^{1} \mathrm{H}$ NMR spectra ( $\mathrm{NH}$ region) of racemic capsules $\mathbf{1}_{\mathbf{2}}$; enantiopure homochiral Fractions (I and II); and the 1:1 mixture of the two; all after the addition of $\mathrm{C}_{70}$. ( $\star$ ) denotes $\mathrm{NH}$ signals corresponding to homochiral capsules; $(\bullet)$ denotes $\mathrm{NH}$ signals corresponding to meso self-assembled capsules.

The $\mathrm{NH}$ region of each homochiral fraction in the presence of $\mathrm{C}_{70}$ showed only three downfield shifted signals, as expected from the high symmetry of the complex and from the strong hydrogen bonds present (Fig. 3). On the contrary, adding $\mathrm{C}_{70}$ to the racemic mixture of $\mathbf{1}$ led to the appearance of additional minor NMR signals, corresponding to non-equivalent $\mathrm{NH}$ protons of meso $\mathbf{1}_{\mathbf{2}}$. Upon mixing both homochiral fractions of 1 , the spectrum obtained in the presence of $\mathrm{C}_{70}$ was identical to that of the capsule resulting from the racemic mixture. It was therefore concluded that homochiral capsules prevail in solution over meso capsules, in a ratio of ca. 7:3.

We finally note that preliminary ${ }^{1} \mathrm{H}$ NMR spectra of a $1: 2$ mixture of racemic $\mathrm{C}_{76}{ }^{[1 \mathrm{~d}]}$ and racemic monomers 1 display a unique set of downfield-shifted signals. ${ }^{[21]}$ This suggests that monomers of 1 are driven to self-assemble into homochiral capsules only (Supporting Information, Fig. S6), with a particular homochiral capsule possibly being favored by a particular enantiomer of $\mathrm{C}_{76}$.

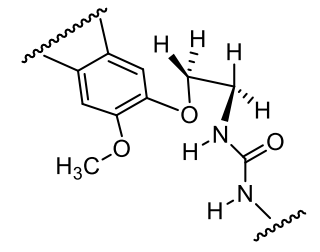

$\mathrm{S}_{\Xi}$

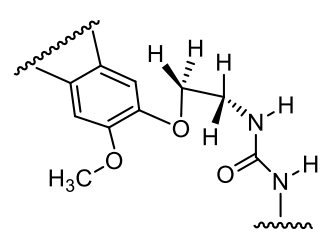

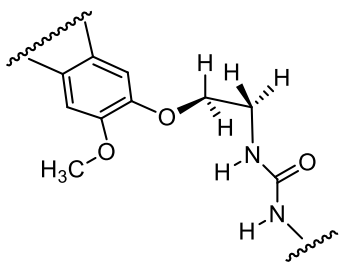

$\mathrm{S}_{\square}$

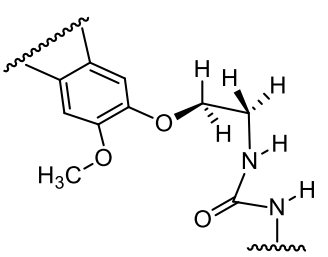

$\mathrm{A}_{\text {घ }}$ 
Figure 4. Possible conformations of the chain linking the CTV and UPy moieties ( $\alpha$ or $\beta$ ); combined with the different possible orientations of CTV and UPy with respect to each other (A or S). See text for details.

Orientation and conformation of CTV-UPy linkers: Upon fullerene encapsulation, the three $\mathrm{O}-\mathrm{CH}_{2} \mathrm{CH}_{2}-\mathrm{N}$ chains linking the CTV and UPy moieties on each 1 (six in total) may adopt one of two possible conformations (Fig. 4). Inspection of a simple CPK capsulefullerene model reveals that the dihedral angle $\mathrm{C}(\mathrm{OMe})-\mathrm{C}-\mathrm{O}-\mathrm{CH}_{2}$ in the six linkers could either be at ca. $90^{\circ}$ (pointing away from the capsule surface, in an orientation that we will henceforth denote as ' $\alpha$ '), or at $180^{\circ}$ (in the plane of the capsule surface, henceforth ' $\beta$ '). A hypothetical conformation at $0^{\circ}$ would on the other hand be sterically inaccessible. Similarly, the dihedral angle about the six $\mathrm{CH}_{2}-$ $\mathrm{CH}_{2}$ bonds $\left(\mathrm{O}-\mathrm{CH}_{2}-\mathrm{CH}_{2}-\mathrm{N}\right)$ must be gauche in order to provide $\mathbf{1}_{\mathbf{2}}$ with the necessary curvature to envelop the almost spherical guest: an anti conformation would instead project the hydrogen-bonded platform away from the fullerene surface. In addition, as also illustrated in Fig. 4, urea NH protons on each UPy could either point away from the $\mathrm{OCH}_{3}$ group of the CTV scaffold (we will refer to this as an A or anti orientation), or in the same direction (S or syn orientation).

All these elements considered, the four most likely conformations of homochiral $\mathbf{1}_{\mathbf{2}}$ should be $S_{\alpha} S_{\alpha}, S_{\beta} S_{\beta}, A_{\alpha} A_{\alpha}$, and $A_{\beta} A_{\beta}$. It also follows that, to maintain hydrogen bonding between their UPy moieties, meso capsules must adopt one of the three conformations $A_{\alpha} S_{\alpha}, A_{\alpha} S_{\beta}$, and $A_{\beta} S_{\alpha}\left(A_{\beta} S_{\beta}\right.$ being inaccessible).

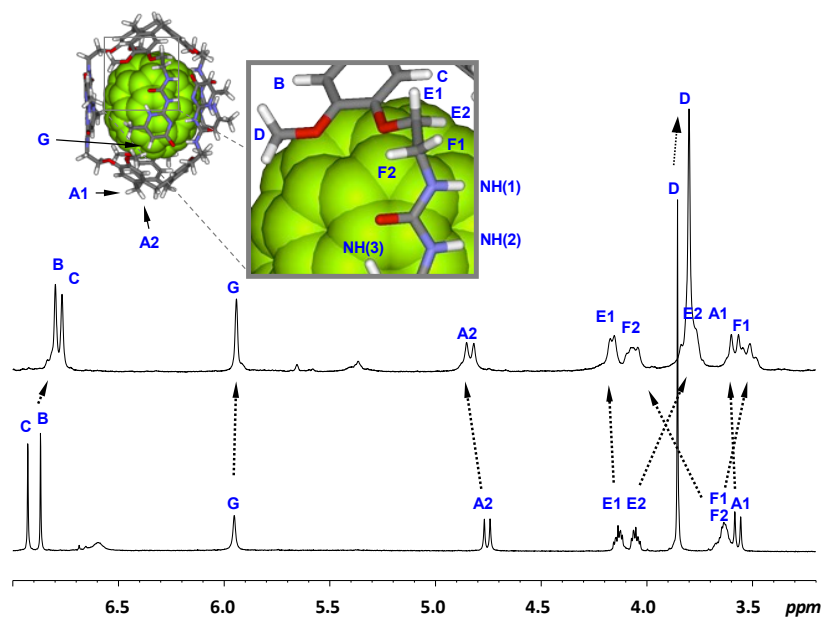

Figure 5. ${ }^{1} \mathrm{H}-\mathrm{NMR}$ spectra $\left(\mathrm{CDCl}_{3}, 400 \mathrm{MHz}, 3.2-7.0 \mathrm{ppm}\right.$ region shown) accounting for the $\mathrm{A}_{\beta} \mathrm{A}_{\beta}$ chain conformation (as shown in model). Bottom spectrum: free monomeric host (1+TFA). Top spectrum: homochiral dimer with $\mathrm{C}_{70}\left(\mathrm{C}_{70} @ 1_{2}\right)$.

Through the use of different NMR techniques, as discussed below, it was possible to establish that conformation $A_{\beta} A_{\beta}$ prevails in solution. All signals were unequivocally assigned by a complement of $2 D$ and $3 D$ (COSY and HSQC) NMR methods (see Supporting Information, Figs. S3 to S5). Aside from the typical deshielding of the three NH signals of each monomer, accounting for a strong hydrogen bonded network (see Fig. 3), the central part of the NMR spectrum is indicative of linker conformation $\alpha$ or $\beta$. Upon encapsulation of $\mathrm{C}_{70}$, several proton signals corresponding to the $\mathrm{O}-\mathrm{CH}_{2}-\mathrm{CH}_{2}-\mathrm{N}$ linker (Fig. 5) did indeed undergo clear upfield or downfield shifts

One of the $\mathrm{CH}_{2}$ protons adjacent to the nitrogen (namely F2), shows an intense vicinal coupling with the proton of the urea, compatible with their mutual anti orientation where the coupling constant reaches a maximum value, ${ }^{[22]}$ and is at the same time strongly deshielded due to its proximity to the carbonyl group. On the contrary, protons C, D, E2, F1, and G, close to the fullerene surface, are shielded. Proton E1, pointing away, clearly remains unaffected. These anisotropic effects are fully compatible with all six UPy-CTV linkers in $\mathbf{1}_{\mathbf{2}}$ adopting the $\beta$ conformation.

On the other hand, the anti $(\mathrm{A})$ rather than syn $(\mathrm{S})$ orientation of $\mathrm{NH}$ protons and methoxy groups was established by means of NOESY experiments (Fig. 6). As per the $A_{\beta} A_{\beta}$ model shown in Fig. 6a, one would expect methoxy protons in CTV (labeled D) to show spatial coupling both with pyrimidinone protons in UPy (labeled G), and with those in the first $\mathrm{CH}_{2}$ of the $\mathrm{C}_{11} \mathrm{H}_{23} \mathrm{Chain}$ (labelled $H$ ). On the contrary, in $S_{\beta} S_{\beta}$ (model in Fig. 6b) spatial coupling would only be expected between $D$ and $G$ protons alone, with $H$ protons in the aliphatic chain being too far to show any spatial coupling. Indeed, the NOESY spectrum of the homochiral $\mathrm{C}_{70} @ 1_{2}$ complex reveals coupling between the spins of all three classes of protons, indicating anti orientation and, hence, $A_{\beta} A_{\beta}$. 


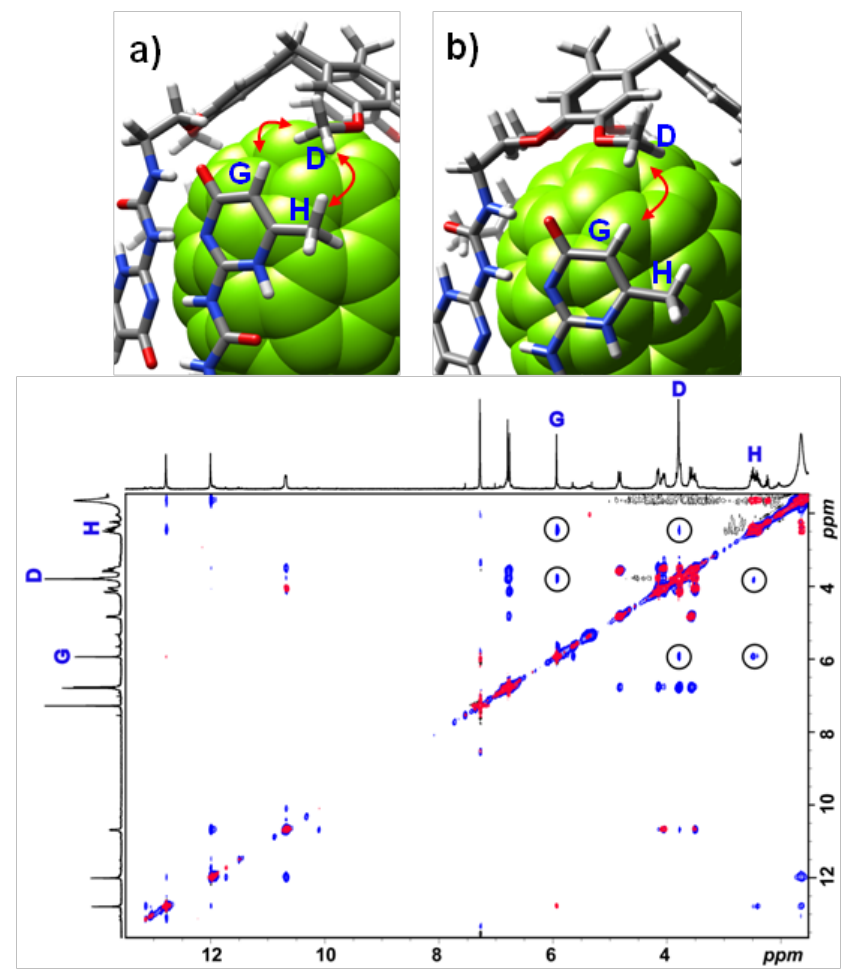

Figure 6. Detail of a) $A_{\beta} A_{\beta}$ and b) $S_{\beta} S_{\beta}$ models showing the spatial proximity of $D, G$ and $H$ protons (top), and partial $\mathrm{NOESY}$ (400 MHz, CDCl ${ }_{3}$, in blue) spectrum of the homochiral $\mathrm{C}_{70} @ \mathbf{1}_{2}$ complex (bottom). H-H COSY (in red) is overlaid for clarity.

\section{Theoretical Studies}

Encapsulation energy components: Encapsulation of $\mathrm{C}_{60}, \mathrm{C}_{70}, \mathrm{C}_{76}, \mathrm{C}_{78}, \mathrm{C}_{84}$ and $\mathrm{C}_{90}$ inside $\mathbf{1}_{2}$ was investigated energetically (vide infra) by carrying out a series of theoretical calculations with the program $A D F$ (v. 2013.01), ${ }^{[23]}$ using density functional theory (DFT) together with dispersion corrections (details in Supporting Information). ${ }^{[18]}$ Coordinates of all optimized fullerene@1 2 structures are also available as Supporting Information; finally, all calculations reported here are also entirely available on-line. ${ }^{[24]}$

For the higher fullerenes $\mathrm{C}_{76}, \mathrm{C}_{78}$, and $\mathrm{C}_{84}$, we choose the isomers that are reported to have the highest experimental abundance: ${ }^{[25]} D_{2}$ (one enantiomer only); ${ }^{[24]} C_{2 v}$; and $D_{2}$ respectively. In the case of $C_{90}$, we choose its $D_{5 h}$ isomer in virtue of its higher symmetry; we also note that this is the most abundant $\mathrm{C}_{90}$ isomer occurring in soot generated from $\mathrm{Sm}_{2} \mathrm{O}_{3}$-doped graphite rods. ${ }^{[26]}$

To begin with (Table 1), $\mathrm{C}_{60}$ and $\mathrm{C}_{70}$ are independently considered inside all of the seven accessible capsule conformers (four homochiral, three meso, as explained earlier). However, for $\mathrm{C}_{76}, \mathrm{C}_{78}, \mathrm{C}_{84}$, and $\mathrm{C}_{90}$ complexes, investigation is subsequently limited to the five $\mathbf{1}_{\mathbf{2}}$ conformers that are shown in Table 1 to yield the most favorable encapsulation energies with $\mathrm{C}_{70}$. Data for four of these $\left(A_{\beta} A_{\beta}, A_{\alpha} A_{\alpha}, S_{\beta} S_{\beta}, A_{\alpha} S_{\beta}\right)$ are plotted in Fig. 7 jointly with some of the data from Table 1, and are fully discussed below; data for the fifth conformer $\left(A_{\beta} S_{\alpha}\right)$ are only plotted in Fig. $S 7$ (Supporting Information) for completeness. We note that in the same Fig. S7, for better visualization, we have also plotted all of the data in Table 1. In practice, omitting conformers $A_{\alpha} S_{\alpha}$ and $S_{\alpha} S_{\alpha}$ from the possible complexes of $\mathrm{C}_{76} @ 1_{2}$ to $\mathrm{C}_{90} @ 1_{2}$ conveniently enabled us to reduce the overall number of species considered from 42 to 34 .

Table 1. Total encapsulation energies $\Delta \mathrm{E}_{\text {tot, }}$, and components thereof (all in $\mathrm{kcal} \cdot \mathrm{mol}^{-1}$; see text for definitions), for fullerenes $\mathrm{C}_{60}$ and $\mathrm{C}_{70}$, inside each of the seven accessible conformations of capsule $\mathbf{1}_{2}$ considered in this work. All are calculated at the BP86-D3(BJ)/TZP level, with the effects of THF implicitly modeled using the conductor-like screening model (COSMO). ${ }^{[27]}$ Graphical plots of these data are provided as Supporting Information (Fig. S7), and are also included in part in Fig. 7.

\begin{tabular}{llll}
$\begin{array}{l}\text { Host } \\
\text { Conformation }\end{array}$ Guest $\Delta \mathrm{E}_{\mathrm{HB} \text { onds }} \quad \Delta \mathrm{E}_{\text {rearr }}$ & $\Delta \mathrm{E}_{\mathrm{H}-\mathrm{G}} \quad \Delta \mathrm{E}_{\text {tot }}$ \\
\hline
\end{tabular}




\begin{tabular}{|c|c|c|c|c|c|}
\hline \multirow[t]{2}{*}{$\mathrm{A}_{\beta} \mathrm{A}_{\beta}$} & $\mathrm{C}_{60}$ & -119.9 & 27.7 & -98.2 & -190.4 \\
\hline & $\mathrm{C}_{70}$ & -116.2 & 21.6 & -119.5 & -214.1 \\
\hline \multirow[t]{2}{*}{$\mathrm{A}_{\alpha} \mathrm{A}_{\alpha}$} & $\mathrm{C}_{60}$ & -110.5 & 24.4 & -100.4 & -186.5 \\
\hline & $\mathrm{C}_{70}$ & -107.5 & 20.7 & -122.2 & -209.1 \\
\hline \multirow[t]{2}{*}{$\mathrm{A}_{\beta} \mathrm{S}_{\alpha}$} & $\mathrm{C}_{60}$ & -112.2 & 31.8 & -97.2 & -177.6 \\
\hline & $\mathrm{C}_{70}$ & -110.0 & 24.3 & -117.3 & -203.0 \\
\hline \multirow[t]{2}{*}{$\mathrm{S}_{\alpha} \mathrm{S}_{\alpha}$} & $\mathrm{C}_{60}$ & -107.2 & 33.0 & -88.7 & -162.8 \\
\hline & $\mathrm{C}_{70}$ & -106.6 & 29.7 & -109.2 & -186.2 \\
\hline \multirow[t]{2}{*}{$\mathrm{S}_{\beta} \mathrm{S}_{\beta}$} & $\mathrm{C}_{60}$ & -100.9 & 22.5 & -103.2 & -181.6 \\
\hline & $\mathrm{C}_{70}$ & -99.4 & 18.7 & -127.3 & -208.1 \\
\hline \multirow[t]{2}{*}{$\mathrm{A}_{\alpha} \mathrm{S}_{\alpha}$} & $\mathrm{C}_{60}$ & -108.9 & 27.4 & -93.8 & -175.2 \\
\hline & $\mathrm{C}_{70}$ & -108.3 & 23.2 & -113.2 & -198.2 \\
\hline \multirow[t]{2}{*}{$A_{\alpha} S_{\beta}$} & $\mathrm{C}_{60}$ & -97.2 & 27.8 & -105.6 & -175.1 \\
\hline & $\mathrm{C}_{70}$ & -105.0 & 19.8 & -122.8 & -208.1 \\
\hline
\end{tabular}

To facilitate its quantification, the total energy released upon host-guest encapsulation $\left(\Delta \mathrm{E}_{\text {tot }}\right)$ is broken up into three smaller components (Eq. 1),

$\Delta \mathrm{E}_{\text {tot }}=\Delta \mathrm{E}_{\mathrm{H}-\mathrm{G}}+\Delta \mathrm{E}_{\mathrm{HBonds}}+\Delta \mathrm{E}_{\text {rearr }}$

each of which is determined separately as defined and discussed below.

We begin by determining the host-guest interaction energy $\left(\Delta \mathrm{E}_{\mathrm{H}-\mathrm{G}}\right)$ for each complex. This is the energy released when a free fullerene is encapsulated in a pre-formed, empty $\mathbf{1}_{2}$ capsule to form a full fullerene@1 $\mathbf{1}_{2}$ complex. The procedure first requires structural optimization of the full fullerene@1 $\mathbf{1}_{2}$ complex; and single-point energy calculations of both the free fullerene and the empty $1_{2}$ capsule. ${ }^{[28]}$ Hence, $\Delta \mathrm{E}_{\mathrm{H}-\mathrm{G}}$ is computed by subtracting the binding energies of the free fullerene and empty capsule from that of optimized fullerene@1.

We should here point out that use of D3(BJ) dispersion corrections in our calculations, ${ }^{[18]}$ as well as implicit inclusion of THF effects using the conductor-like screening model (COSMO; details in Supporting Information), ${ }^{[27]}$ were both considered essential to

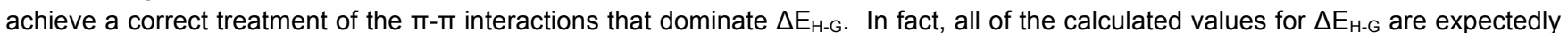
large and negative (attractive). Our goal in this study is merely that of qualitatively comparing relative host-fullerene stabilities, rather than quantifying association constants. Nonetheless, we should still note that Grimme, Antony, and Sure additionally recommend to include entropic contributions when treating supramolecular complexes of this kind. ${ }^{[29]}$

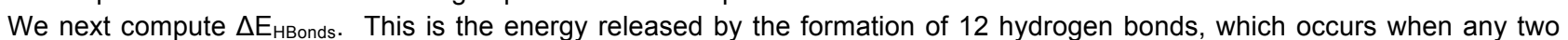
individual CTV-UPy monomers 1, already rearranged (deformed) into their respective capsule conformations (i.e. S or A; $\alpha$ or $\beta$ ), combine to form an empty capsule $\mathbf{1}_{\mathbf{2}}$. Quantification of $\Delta \mathrm{E}_{\mathrm{HBonds}}$, which is also always found to be negative, only requires additional single-point energy calculations to be separately carried out on the two instances of $\mathbf{1}$ composing $\mathbf{1}_{\mathbf{2}}$, still in their deformed states; binding energies thus obtained are simply subtracted from the binding energy of $\mathbf{1}_{\mathbf{2}}$, which is already known from the calculation of $\Delta \mathrm{E}_{\mathrm{H}-\mathrm{G}}$.

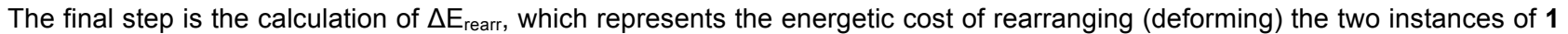
from their optimal state in solution to the conformation they will adopt to form $\mathbf{1}_{2}$. Quantification of $\Delta \mathrm{E}_{\text {rearr }}$ thus requires both halfcapsules to be fully and separately optimized. The value is obtained by subtracting the binding energy of each optimized 1 from that of its rearranged (unoptimized) counterpart, and is the only component of $\Delta \mathrm{E}_{\text {tot }}$ to have a positive value. It also follows from this that the sum of $\Delta \mathrm{E}_{\mathrm{HBonds}}$ and $\Delta \mathrm{E}_{\text {rearr }}$ actually determines the total energy released upon formation of an empty capsule.

Energy studies on complexes of $\mathbf{C}_{60}$ and $\mathbf{C}_{70}$ : We begin by commenting values and trends in detail for $\mathrm{C}_{60}$ and $\mathrm{C}_{70}$ (Table 1 ; leftmost points in Fig. 7); then proceed to examine them for remaining fullerenes (Fig. 7) from a more general point of view. 
Turning first to $\Delta \mathrm{E}_{\text {rearr }}$ values in Table 1, we find that, for encapsulation of both $\mathrm{C}_{60}$ and $\mathrm{C}_{70}$, monomers composing the $\mathrm{S}_{\beta} \mathrm{S}_{\beta}$ capsule have the lowest cost of deformation. In the case of $\mathrm{C}_{60} @ \mathbf{1}_{2}$, these are followed by $\mathrm{A}_{\alpha} \mathrm{A}_{\alpha}$ capsule monomers, and, in third place, by monomers composing $A_{\alpha} S_{\alpha}, A_{\beta} A_{\beta}$, and $A_{\alpha} S_{\beta}$ (all bearing similar deformation costs). For $C_{70} @ 1_{2}$, on the other hand, $A_{\alpha} A_{\alpha}$ capsule monomers are beaten into third place by $A_{\alpha} S_{\beta}$ capsule monomers, whose $\Delta E_{\text {rearr }}$ drops more markedly. The highest cost of rearrangement is instead borne by monomers of the $S_{\alpha} S_{\alpha}$ capsule, both in the case of $C_{60}$ and in the case of $C_{70}$.

In terms of $\Delta \mathrm{E}_{\mathrm{HB} \text { onds }}$ (cf. Table 1 again), the most favorable values for $\mathrm{C}_{60} @ \mathbf{1}_{\mathbf{2}}$ and $\mathrm{C}_{70} @ \mathbf{1}_{\mathbf{2}}$ complexes are found when $\mathbf{1}_{\mathbf{2}}$ is in $A_{\beta} A_{\beta}$ conformation, followed by values for $1_{2}$ in the $A_{\beta} S_{\alpha}$ conformation (ca. 6-8 kcal mol ${ }^{-1}$ higher). The third most favorable $\Delta E_{H B o n d s}$ values are for $\mathbf{1}_{\mathbf{2}}$ in the $A_{\alpha} A_{\alpha}$ conformation in the case of $C_{60} @ \mathbf{1}_{2}$, and in the $A_{\alpha} S_{\alpha}$ conformation in the case of $C_{70} @ 1_{2}$. On the other hand, the most unfavorable $\Delta E_{H B o n d s}$ values are found for $\mathbf{1}_{2}$ in the $A_{\alpha} S_{\beta}$ and $S_{\beta} S_{\beta}$ conformations.

The most favorable $\Delta \mathrm{E}_{\mathrm{H}-\mathrm{G}}$ values in the case of $\mathrm{C}_{60}$ and $\mathrm{C}_{70}$ (Table 1) were obtained for their interactions with the $A_{\alpha} S_{\beta}$ and $S_{\beta} S_{\beta}$ capsules, with the former prevailing over the latter in the case of $\mathrm{C}_{60}$, and vice versa in the case of $\mathrm{C}_{70}$. At third place for both fullerenes are the $\Delta \mathrm{E}_{\mathrm{H}-\mathrm{G}}$ values calculated for the homochiral capsule $\mathrm{A}_{\alpha} \mathrm{A}_{\alpha}$; the least favorable host-guest contacts are made in the $\mathrm{S}_{\alpha} \mathrm{S}_{\alpha}$ capsule.

Thus, upon summing the three components as per Eq. 1, the most favorable (negative) $\Delta \mathrm{E}_{\text {tot }}$ overall for both $\mathrm{C}_{60} @ \mathbf{1}_{\mathbf{2}}$ and $\mathrm{C}_{70} @ 1_{2}$ is obtained with the capsule $\mathrm{A}_{\beta} \mathrm{A}_{\beta}$, aided by its moderate-to-strong favorability in $\Delta \mathrm{E}_{\mathrm{H}-\mathrm{G}}$ and $\Delta \mathrm{E}_{\text {rearr }}$. The second-best capsule for both fullerenes is the syn counterpart $S_{\beta} S_{\beta}$, followed by $A_{\alpha} A_{\alpha}$ in the case of $C_{60}$ and $A_{\alpha} S_{\beta}$ in the case of $C_{70}$ (the sole occurrence of a meso capsule).

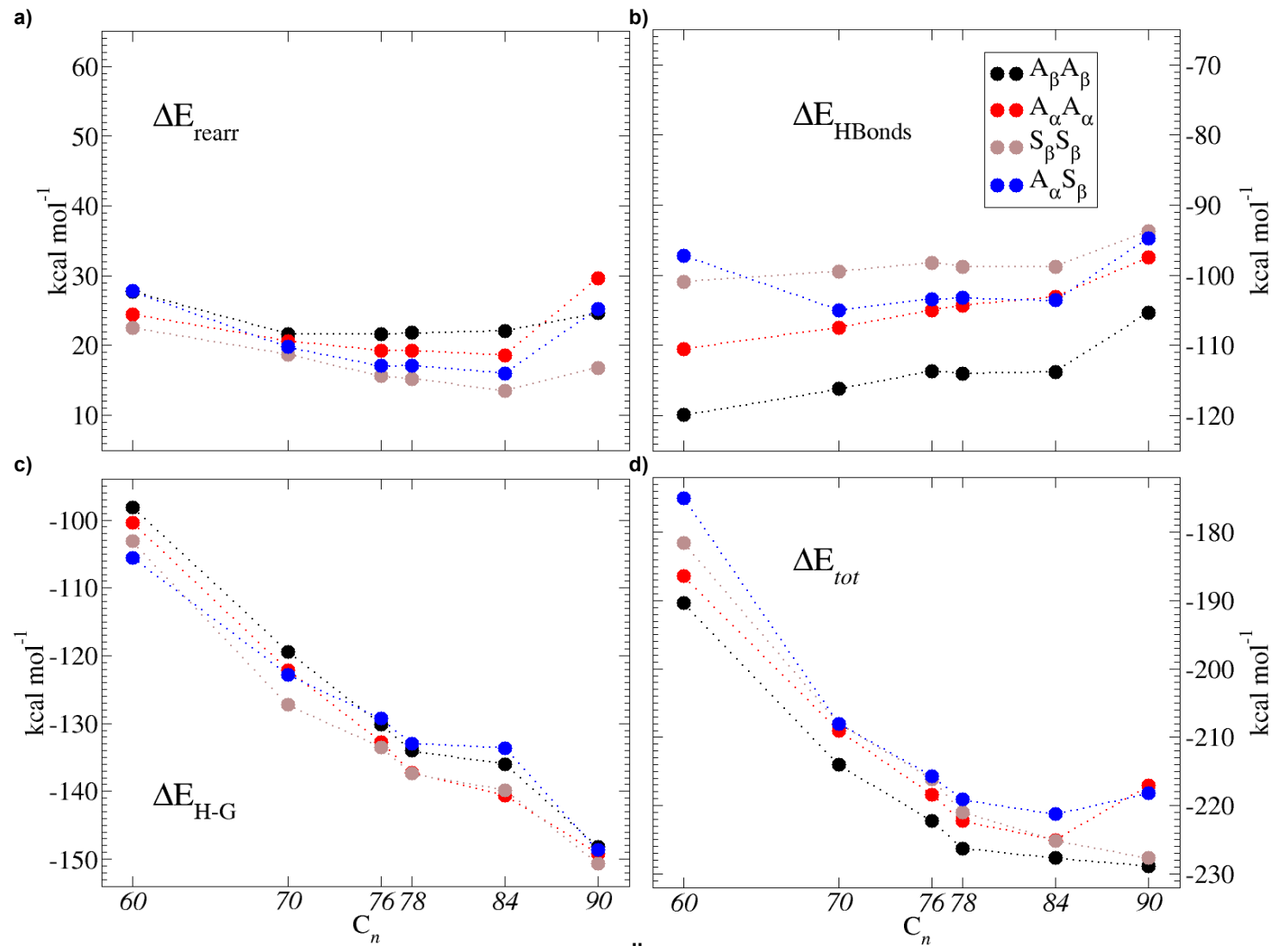

Figure 7. Evolution of a) $\Delta \mathrm{E}_{\text {rearr; }}$ b) $\Delta \mathrm{E}_{\mathrm{HBonds}}$; c) $\Delta \mathrm{E}_{\mathrm{H}-\mathrm{G}}$; and d) $\Delta \mathrm{E}_{\text {tot }}$ (cf. Eq. 1) for fullerenes $\mathrm{C}_{60}, \mathrm{C}_{70}, \mathrm{C}_{76}, \mathrm{C}_{78}, \mathrm{C}_{84}$, and $\mathrm{C}_{90}$ encapsulated within the four most energetically favored conformations of $C_{70} @ 1_{2}$ (cf. Table 1): $A_{\beta} A_{\beta}, A_{\alpha} A_{\alpha}, S_{\beta} S_{\beta}$, and $A_{\alpha} S_{\beta}$. Numerical values for each of these plots are also provided as Supporting Information (Table $\mathrm{S} 1$ ), and those for $\mathrm{C}_{60}$ and $\mathrm{C}_{70}$ also appear in Table 1. The color code is explained in $\mathbf{b}$ ); lines are guides for the eye. All values are calculated at the BP86-D3(BJ)/TZP level.

Upon analyzing the trends when moving from $\mathrm{C}_{60}$ to $\mathrm{C}_{70}$, we should first of all note a generalized decrease in all $\Delta \mathrm{E}_{\text {rearr }}$ values (cf. two leftmost points in Fig. 7a and, more exhaustively, Fig. S7a), meaning that deformation of host monomers is always energetically cheaper when accepting the latter guest. The decrease in cost ranges from $-3.4 \mathrm{kcal} \mathrm{mol}^{-1}\left(\mathbf{1}_{\mathbf{2}}\right.$ in $\mathrm{S}_{\alpha} \mathrm{S}_{\alpha}$ conformation) to as much as $-8.0 \mathrm{kcal} \mathrm{mol}^{-1}\left(\mathbf{1}_{\mathbf{2}}\right.$ in $\left.\mathrm{A}_{\alpha} \mathrm{S}_{\beta}\right)$. 
For six of the seven hosts, $\Delta \mathrm{E}_{\mathrm{HBonds}}$ (Figs. $7 \mathrm{~b}$ and $\mathrm{S} 7 \mathrm{~b}$ ) is roughly similar with $\mathrm{C}_{60}$ and $\mathrm{C}_{70}$ alike, with only a slight decrease in favorability observed when hosting the latter fullerene $\left(+0.5\right.$ to $\left.+3.7 \mathrm{kcal} \cdot \mathrm{mol}^{-1}\right)$. On the other hand, $A_{\alpha} S_{\beta}$ is in this case an evident outlier: its hydrogen bond formation when hosting $\mathrm{C}_{70}$ is actually decisively more favorable (negative) by as much as $-7.9 \mathrm{kcal} \mathrm{mol}^{-1}$.

This unusual favorable trend in $\Delta \mathrm{E}_{\mathrm{HB} \text { nds }}$, combined with the aforementioned highest decrease in $\Delta \mathrm{E}_{\text {rearr, }}$ means that, when switching the guest from $\mathrm{C}_{60}$ to $\mathrm{C}_{70}$, the total energy of forming the $\mathrm{A}_{\alpha} \mathrm{S}_{\beta}$ capsule from free monomers of 1 (i.e. $\Delta \mathrm{E}_{\mathrm{HB} \text { Bnds }}+\Delta \mathrm{E}_{\text {rearr }}$ ) undergoes an exceptionally high increase in favorability $\left(-15.8 \mathrm{kcal} \mathrm{mol}^{-1}\right)$. Such an increase is far more modest in the six remaining capsules, ranging from $-0.8$ $-5.3 \mathrm{kcal} \mathrm{mol}^{-1}$.

It is nonetheless equally evident that the remaining component $\Delta \mathrm{E}_{\mathrm{H}-\mathrm{G}}$ (cf. leftmost points in Figs. 7c and $\mathrm{S} 7 \mathrm{c}$ ) has by far the largest influence on $\Delta \mathrm{E}_{\text {tot }}$ (Figs. $7 \mathrm{~d}$ and $\mathrm{S} 7 \mathrm{~d}$ ). Indeed, as more $\pi-\pi$ interactions are formed once $\mathrm{C}_{60}$ is replaced by $\mathrm{C}_{70}$, capsulefullerene interaction energies become more favorable (negative) by as much as -17.2 to $-24.1 \mathrm{kcal} \mathrm{mol}^{-1}$ : all six these increases in favorability far outrank those observed for $\Delta \mathrm{E}_{H B \text { Bnds }}$ and $\Delta \mathrm{E}_{\text {rearr }}$ combined, even in the case of the outlier conformer $\mathrm{A}_{\alpha} \mathrm{S}_{\beta}$.

All these factors considered, it comes as no surprise that $\Delta \mathrm{E}_{\text {tot }}$ is always significantly more favorable for $\mathrm{C}_{70} @ \mathbf{1}_{2}$ than it is for $\mathrm{C}_{60} @ 1_{2}$, regardless of what conformation $\mathbf{1}_{2}$ is in. Gains in favorability range from $-22.6 \mathrm{kcal} \mathrm{mol}^{-1}$ for the formation of $\mathrm{C}_{70} @ \mathrm{~A}_{\alpha} \mathrm{A}_{\alpha}$ over $\mathrm{C}_{60} @ \mathrm{~A}_{\alpha} \mathrm{A}_{\alpha}$ to the $-33.0 \mathrm{kcal} \mathrm{mol}^{-1}$ of $\mathrm{C}_{70} @ \mathrm{~A}_{\alpha} \mathrm{S}_{\beta}$ over $\mathrm{C}_{60} @ \mathrm{~A}_{\alpha} \mathrm{S}_{\beta}$, which of course benefits from the unexpected trend in $\Delta \mathrm{E}_{\mathrm{HB} \text { onds. }}$

Energy studies on remaining complexes: We now turn to complexes of fullerenes $\mathrm{C}_{76}, \mathrm{C}_{78}, \mathrm{C}_{84}$, and $\mathrm{C}_{90}$, which we here only discuss with $\mathbf{1}_{2}$ in $A_{\beta} A_{\beta}, A_{\alpha} A_{\alpha}, S_{\beta} S_{\beta}, A_{\alpha} S_{\beta}$ conformation (and with $\mathbf{1}_{2}$ in $A_{\beta} S_{\alpha}$ conformation as Supporting Information). In this part of the discussion, we shall hence refer to the four plots in Fig. 7 in their entirety, and from a qualitative point of view; the reader is nonetheless reminded that values for these plots are fully tabulated in Table S1.

The four plots of $\Delta \mathrm{E}_{\text {tot }}$ and its components all reveal an interesting evolution beyond $\mathrm{C}_{70}$ : examining these in the same order as before, we begin with $\Delta E_{\text {rearr }}$ (Fig. 7a). The first thing to note is that the cost of rearranging $S_{\beta} S_{\beta}$ monomers consistently remains the lowest right up to $C_{90}$. The highest cost is borne by $A_{\beta} A_{\beta}$ up to $C_{84}$; in the case of the largest guest $C_{90}$, however, rearrangement costs of both the $A_{\alpha} S_{\beta}$ and $A_{\alpha} A_{\alpha}$ capsules undergo a late 'surge' whereby they overtake $A_{\beta} A_{\beta}$. More in general, a late surge in $\Delta E_{\text {rearr }}$ is observed in all four capsule conformers considered, even though it is evidently more modest for $S_{\beta} S_{\beta}$ and $A_{\beta} A_{\beta}$. In the case of $A_{\beta} A_{\beta}$, this (very modest) surge already begins between $C_{70} @ A_{\beta} A_{\beta}$ and $C_{76} @ A_{\beta} A_{\beta}$; on the other hand, when moving from $C_{70}$ to $C_{84}$, $\Delta \mathrm{E}_{\text {rearr }}$ of remaining conformers is seen to decrease slightly.

In the case of $\Delta E_{H B o n d s}$ (Fig. $7 b$ ), the general order of favorability detected for $C_{70}$ is preserved up to $C_{90}$, with $A_{\beta} A_{\beta}$ the most favorable $1_{2}$ conformer, $S_{\beta} S_{\beta}$ the most unfavorable, and $A_{\alpha} S_{\beta}$ and $A_{\alpha} A_{\alpha}$ tending to be close together, and in between. Between $C_{70}$ and $\mathrm{C}_{84}$, the favorability of forming hydrogen bonds shows almost no variation, but once more, there is a surge in unfavorability $\left(\Delta \mathrm{E}_{\mathrm{HBonds}}\right.$ less negative) between $\mathrm{C}_{84}$ and $\mathrm{C}_{90}$.

Trends in $\Delta \mathrm{E}_{\mathrm{H}-\mathrm{G}}$ (Fig. 7c) are far more uniform, even though the order of favorability changes frequently between capsule conformers. For example, $A_{\alpha} S_{\beta}$ is the conformer that exhibits the most favorable host-guest interaction with $C_{60}$, but the least favorable with $C_{90}$; also, for guests between $C_{76}$ and $C_{90}$, the most favorable $\Delta E_{H-G}$ values are alternatively found for $A_{\alpha} A_{\alpha}$ and $S_{\beta} S_{\beta}$. Despite this, all plots clearly show that, except for a hump at $\mathrm{C}_{84}$, all host-guest interactions undergo a consistently large increase in favorability, with $\mathrm{C}_{90}$ more favored than $\mathrm{C}_{60}$ by, on average, $47 \mathrm{kcal} \mathrm{mol}^{-1}$.

Exactly as observed for $\mathrm{C}_{60}$ and $\mathrm{C}_{70}$, such predominance of $\Delta \mathrm{E}_{\mathrm{H}-\mathrm{G}}$ over $\Delta \mathrm{E}_{\text {rearr }}$ and $\Delta \mathrm{E}_{\mathrm{HBonds}}$ is fully reflected in $\Delta \mathrm{E}_{\text {tot }}$ plots for encapsulation of guests up to $\mathrm{C}_{84}$ (Fig. $7 \mathrm{~d}$ ). However, the late surges in $\Delta \mathrm{E}_{\text {rearr }}$ and $\Delta \mathrm{E}_{\mathrm{HBonds}}$ observed between $\mathrm{C}_{84}$ and $\mathrm{C}_{90}$ begin to counteract the beneficial effects of $\Delta \mathrm{E}_{\mathrm{H}-\mathrm{G}}$ and as a consequence, between $\mathrm{C}_{78}$ and $\mathrm{C}_{90}, \Delta \mathrm{E}_{\text {tot }}$ plots are seen to approach plateaus. In fact, in the case of $A_{\alpha} A_{\alpha}$, the trend is even reversed: encapsulation of $C_{90}$ by $A_{\alpha} A_{\alpha}$ actually returns to be less favorable than $C_{76}$.

Most crucially, it can also be concluded that the affinity of all capsule conformers towards $\mathrm{C}_{84}$ is higher than that towards $\mathrm{C}_{70}$, which in turn is significantly higher than that towards $\mathrm{C}_{60}$ : this is fully consistent with the experimental results. ${ }^{[14-15]}$ Moreover, it can be seen that $A_{\beta} A_{\beta}$ is consistently found to have the most favorable $\Delta E_{\text {tot }}$ values with respect to all other conformers: such energetic preference is also in full agreement with our NMR results. Based on these results, we can establish a scale of affinity as follows between the $\boldsymbol{1}_{2}$ capsule and the set of fullerenes studied: $\mathrm{C}_{60}<\mathrm{C}_{70}<\mathrm{C}_{76}<\mathrm{C}_{78}<\mathrm{C}_{84} \approx \mathrm{C}_{90}$.

Structural studies: Table 2 lists a series of key geometric parameters, measured in each of the six optimized fullerene@12 complexes evaluated in this study, only considering $\mathbf{1}_{\mathbf{2}}$ capsules in the $A_{\beta} A_{\beta}$ conformation due to its detected energetic preference, both theoretically and experimentally. Where possible, these are compared with equivalent parameters obtained for an optimized empty $\mathbf{1}_{\mathbf{2}}$ in the same conformation, and at the same level of theory. Atoms are numbered according to the scheme illustrated in Table 2, whose footnotes explain the parameters in more detail.

$(\mathrm{N}) \mathrm{H} \cdots \mathrm{O}$ hydrogen bond lengths (2-8' / 2'-8) are very similar in all cases, and generally close to their value of $1.658 \AA$ in the empty $A_{\beta} A_{\beta}$ capsule; furthermore values do not show any particular trend in relation to increasing guest size. On the other hand, deviation from the empty capsule is more evident in the case of central $(\mathrm{N}) \mathrm{H} \cdots \mathrm{N}$ bond lengths (4-6' / 4'-6), which are all longer than the $1.815 \AA$ template. As guest size progressively increases from $C_{60} / C_{70}$ to $C_{84}$, so do bond lengths $(1.823 / 1.820$ to $1.848 \AA)$; for the even larger but decidedly prolate $\mathrm{C}_{90}$, equatorial strain on $\mathbf{1}_{2}$ is released, and $(\mathrm{N}) \mathrm{H} \cdots \mathrm{N}$ distances return to $1.829 \AA$. 
Angles associated with these hydrogen bonds (1-2-8' / 1'-2'-8 and 3-4-6' / 3'-4'-6, respectively) show degrees of correlation with guest size that are similar to those of their parent bonds. In the case of 1-2-8' / 1'-2'-8, we again see little correlation with fullerene size, although angles in all complexes (except for $172.5^{\circ}$ in $\mathbf{C}_{90} @ \mathbf{1}_{\mathbf{2}}$ ) are consistently found to be smaller than the $169.9^{\circ}$ of empty $\mathbf{1}_{\mathbf{2}}$ $\left(166.7^{\circ}\right.$ to $\left.167.7^{\circ}\right)$. On the other hand, 3-4-6' / 3'-4'-6 angles exhibit an extremely interesting evolution with fullerene size. First of all, mirroring the trend in 2-8' / 2'-8 bonds (all longer than in the free dimer), all angles are found to be less planar than the $178.0^{\circ}$ found in the empty capsule. Even more importantly, if their degree of deviation from $178.0^{\circ}$ is plotted against fullerene size, one can see (Fig. 8) that it is almost superimposable on the $\Delta E_{H B o n d s}$ plot for the $A_{\beta} A_{\beta}$ capsule; this suggests that 3-4-6' / 3'-4'-6 angles and their associated 'equatorial' hydrogen bonds have a particularly important effect on the overall energy released upon hydrogen bond formation.

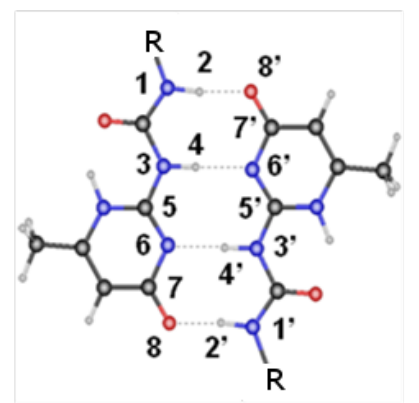

Table 2. Average geometric parameters measured in optimized fullerene@ $\mathbf{1}_{\mathbf{2}}$ complexes, and in the empty $\mathbf{1}_{\mathbf{2}}$ capsule, with $\mathbf{1}_{\mathbf{2}}$ always in $\mathrm{A}_{\beta} \mathrm{A}_{\beta}$ conformation. Distances are reported in $\AA$; angles in ${ }^{\circ}$. All parameters are averages, except the distance between CTV domes, of which there is only one instance in every $\mathbf{1}_{\mathbf{2}}$. Parameters are numbered according to the scheme in the above inset.

\begin{tabular}{|c|c|c|c|c|c|c|c|}
\hline Average Parameter & No guest & $\mathrm{C}_{60}$ & $\mathrm{C}_{70}$ & $\mathrm{C}_{76}$ & $\mathrm{C}_{78}$ & $\mathrm{C}_{84}$ & $\mathrm{C}_{90}$ \\
\hline Dist 2-8' / 2'-8 & 1.658 & 1.652 & 1.660 & 1.659 & 1.654 & 1.651 & 1.662 \\
\hline Angle 1-2-8' / 1'-2'-8 & 169.9 & 166.7 & 167.2 & 167.2 & 167.7 & 167.3 & 172.5 \\
\hline Angle 3-4-6' / 3'-4'-6 & 178.0 & 174.7 & 172.4 & 171.8 & 172.4 & 173.2 & 171.6 \\
\hline Angle $\mathrm{CTV}^{[\mathrm{b}]}$ & $109.5^{[\mathrm{c}]}$ & 102.3 & 107.6 & 110.5 & 112.1 & 113.0 & 113.7 \\
\hline Dist UPy ${ }^{[d]}$ & - & 10.8 & 10.9 & 11.2 & 11.1 & 11.9 & 11.0 \\
\hline Average $\mathrm{H}-\mathrm{G}$ distance ${ }^{[\mathrm{e}]}$ & - & 3.275 & 3.288 & 3.230 & 3.212 & 3.207 & 3.162 \\
\hline
\end{tabular}

[a] Distance between the two centroids at the middle of each CTV macro-ring. [b] Angle formed by the centroids of two adjacent CTV aromatic rings and their methylene bridging carbon. [c] Free monomer 1 in $A_{\beta}$ conformation. [d] Average distance from centroids of two 3-5 bonds in adjacent UPy dimers. [e] Average of the distance between each guest atom and its closest host atom. 


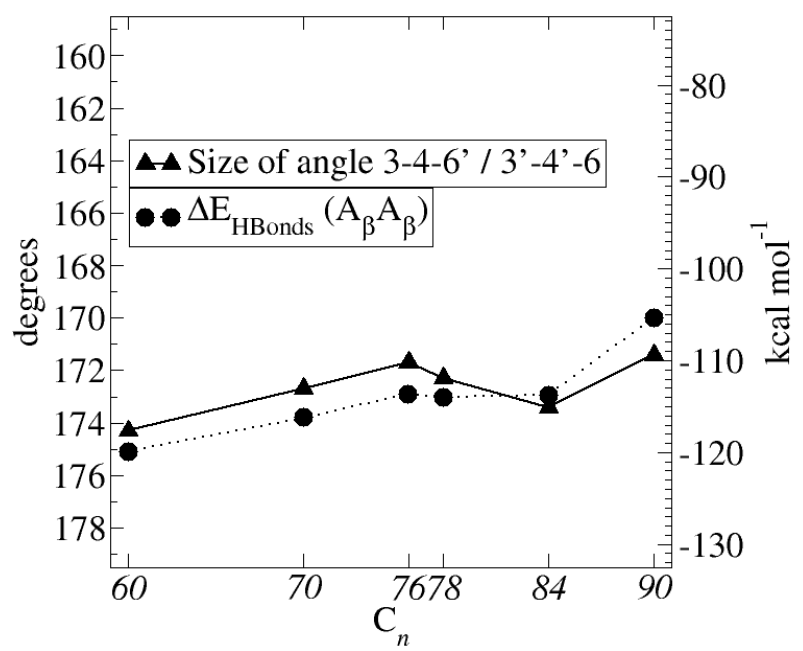

Figure 8. Size of the angle 3-4-6' / 3'-4'-6 in ${ }^{\circ}$ (cf. Table 2), superimposed on the $\Delta \mathrm{E}_{\mathrm{Hbonds}}$ plot for $\mathrm{A}_{\beta} \mathrm{A}_{\beta}$ capsule-fullerene complexes (cf. Fig. $7 \mathrm{~b}$ ). Note the inverted scale for the angle plot.

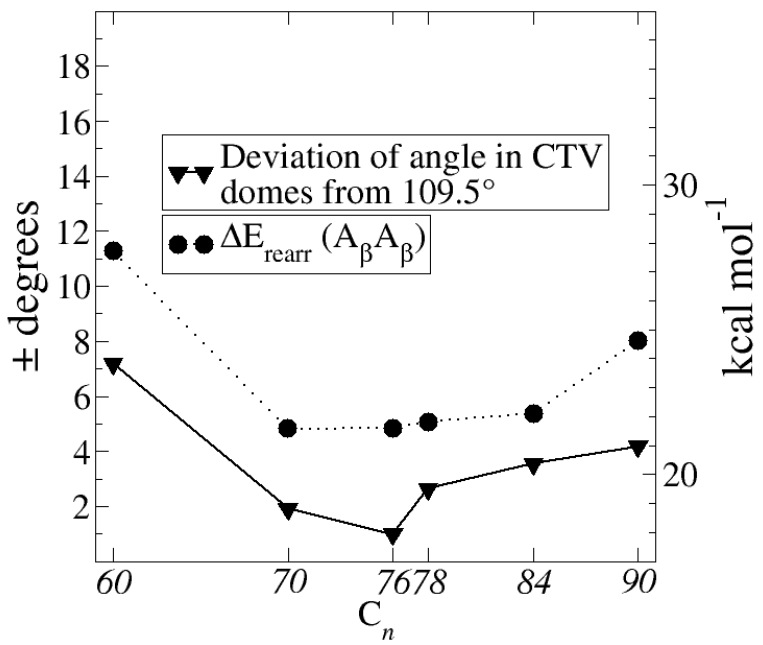

Figure 9. Deviation from $109.5^{\circ}$ of the average angle between CTV ring centroids and $\mathrm{CH}_{2}$ units; superimposed on the $\Delta \mathrm{E}_{\text {rearr }}$ plot for $\mathrm{A}_{\beta} \mathrm{A}_{\beta}$ capsule-fullerene complexes (cf. Fig. 7a).

Turning to the two CTV 'domes', the distance between their centroids remains constant at $16.4 \AA$ for the quasi-spherical guests $\mathrm{C}_{60}$ to $\mathrm{C}_{78}$, and drops to $15.7 \AA$ for $\mathrm{C}_{84}$. On the contrary, for the prolate guest $\mathrm{C}_{90}$ we observe an elongation to $17.4 \AA$, much closer to the $17.7 \AA$ observed in the free $A_{\beta} A_{\beta}$ capsule.

At any rate, the most striking parameter related to CTV is the average angle formed by the centroids of the aromatic rings and methylenic carbons in the dome: this has a clear correlation with guest size, and consistently increases from $102.3^{\circ}$ in $\mathrm{C}_{60} @ 1_{2}$ to $113.7^{\circ}$ in $\mathbf{C}_{90} @ 1_{2}$. We furthermore note that the corresponding angle in optimized monomer 1 ( $A_{\beta}$ conformation) is $109.5^{\circ}$ : if the magnitude of the deviation from $109.5^{\circ}$ is plotted for each of the six fullerene@ $\mathbf{1}_{\mathbf{2}}$ complexes against fullerene size, we find that there is rough agreement with the plot for $\Delta \mathrm{E}_{\text {rearr }}$ (Fig. 9). In other words, this suggests that squeezing $\left(\mathrm{C}_{60}, \mathrm{C}_{70}\right)$ or stretching $\left(\mathrm{C}_{76}\right.$ to $\left.\mathrm{C}_{90}\right)$ CTV angles constitutes a significant part of the overall cost of deforming capsule monomers 1 from their optimized state.

The lack of trends in the distance between $\mathrm{UPy}_{2}$ centroids $(10.8-11.9 \AA)$, which is similar to the absence of patterns in $(\mathrm{N}) \mathrm{H} \cdots \mathrm{O}$ lengths and angles, is another indication that the increasing geometric distortion caused by increasing fullerene size is mainly distributed at the 'CTV poles' of the capsules rather than at their 'UPy equator'. Nonetheless, ( $N$ ) $\mathrm{H}^{\cdots \mathrm{N}}$ bonds are obviously still distorted to some extent too.

Finally, we set out to measure, in each host-guest complex, the average of the shortest contacts between guest atoms and host atoms: mean values for such contacts are tabulated in the last line of Table 2. It is clear from these values that the contacts made by 
$\mathrm{C}_{60}(3.275 \AA)$ and $\mathrm{C}_{70}(3.288 \AA)$ are the loosest, and that there is a progressive increase in tightness before reaching $\mathrm{C}_{84}(3.207 \AA)$ and $\mathrm{C}_{90}(3.162 \AA)$. Increasingly tight contacts help to explain the increasing energetic favorability (negativity) of $\Delta \mathrm{E}_{\mathrm{H}-\mathrm{G}}$, which in turn so strongly contributes to the overall $\Delta \mathrm{E}_{\text {tot. }}$.

\section{Thermal Stability vs. Racemization of Homochiral Capsules}

In the opening part of this section, we presented experimental evidence on some structural aspects of the $\mathbf{1}_{\mathbf{2}}$ capsules and their complexes with fullerenes, namely: tautomerism of the UPy dimeric subunits; conformation of the linker chain between the CTV platform and the UPy subunits; and orientation of methoxy groups in CTV with respect to urea protons in UPy (in turn linked to the homochiral or meso nature of the $\mathbf{1}_{\mathbf{2}}$ capsules). These observations helped to reduce the amount of DFT calculations, by restricting conformational space to explore and the number of isomers to consider. The outcome of the calculations is also in agreement with experiment, with the trend in energetic stabilities $C_{84}>C_{70}>C_{60}$ perfectly matching selectivities observed in fullerenes extraction from fullerite. To complement these observations on energetic stabilities, we performed a study on how different fullerenes affect the racemization rate of homochiral capsules.

Racemization requires a complete inversion of the CTV domes in capsule monomers: this means that in order for it to occur, dimeric capsules must break at least in part. Consequently, one should expect racemization to be more favored for the less stable host-guest complexes, and our study should enable us to establish a link between stability and racemization rate. The rate of the "crown-to-crown" interconversion leading to racemization is also sensitive to temperature, ${ }^{[20,30]}$ and we make use of this in our study.

Thus, racemization of free host monomers 1 was monitored by CD in tetrachloroethane at three different temperatures, and compared to racemization in $\mathrm{C}_{60} @ \mathbf{1}_{2}, \mathrm{C}_{70} @ \mathbf{1}_{\mathbf{2}}$, and $\mathrm{C}_{84} @ \mathbf{1}_{\mathbf{2}}$ under the same conditions. Spectra were collected every ten minutes until total racemization took place (Supporting Information, Figs. S8 to S12). In all cases, racemization was seen to follow first order kinetics. Thermodynamic parameters derived from kinetic data (Supporting Information, Table S2) were fitted to Eyring plots (Fig. S13).

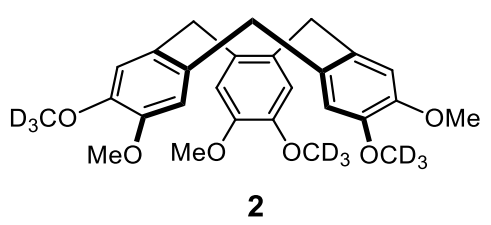

Figure 10. Deuterated CTV derivative 2, studied by Collet and Gabard. ${ }^{[30]}$

Table 3. Thermodynamic transition state parameters (all in $\mathrm{kcal} \mathrm{mol}^{-1}$ ) of CTV derivatives 1 and $2 ;{ }^{[30]}$ and the complexes of $\mathbf{1}_{\mathbf{2}}$ with fullerenes $\mathrm{C}_{60}, \mathrm{C}_{70}$, and $\mathrm{C}_{84}$.

\begin{tabular}{lllll}
\hline Compound & $\mathrm{E}_{\mathrm{a}}^{[\mathrm{a}]}$ & $\Delta \mathrm{H}$ & $\Delta \mathrm{S}$ & $\Delta \mathrm{G}^{[\mathrm{b}]}$ \\
\hline $\mathbf{1}$ & 23.9 & 23.3 & $-5.6 \times 10^{-3}$ & 25.0 \\
$\mathrm{C}_{60} @ 1_{2}$ & 33.0 & 32.4 & $20.8 \times 10^{-3}$ & 26.2 \\
$\mathrm{C}_{70} @ 1_{2}$ & 38.5 & 37.9 & $35.4 \times 10^{-3}$ & 27.4 \\
$\mathrm{C}_{84} @ \mathbf{1}_{2}$ & 66.0 & 65.6 & $121.8 \times 10^{-3}$ & 29.3 \\
$\mathbf{2}^{[30]}$ & 26.5 & 25.9 & $-1.9 \times 10^{-3}$ & 26.5 \\
\hline
\end{tabular}

[a] Values derived from the Arrhenius equation. [b] At $298 \mathrm{~K}$.

For 1, thermodynamic parameters associated with racemization (Table 3) were very similar to those obtained by Collet and Gabard $^{[30]}$ for the racemization of monomers of their compound 2 (Fig. 10), despite the fact that these are deuterated, and therefore unable to dimerize.

For filled homochiral capsules, on the other hand, racemization rates definitely showed dependence on the volume of the included guest: indeed, the enthalpic barrier $\Delta \mathrm{H}$. clearly increases with fullerene size, in full agreement with the higher stabilities found by calculations, and the previously determined binding constants. ${ }^{[15]}$ We nonetheless note that, possibly due to the greater rotational frustration suffered by larger fullerenes after encapsulation, the entropic barrier $\Delta \mathrm{S}$ - is also seen to increase with guest size: as a result, at $298 \mathrm{~K}$, enthalpy-entropy compensation restores free energies of activation $(\Delta G$ ) $)$ to more or less similar values. 


\section{Conclusions}

We have herein reported a series of experimental $\left({ }^{1} \mathrm{H} N M R, C D\right)$ and theoretical studies (dispersion-corrected DFT) on a series of dimeric capsules, in different conformations, hosting six different fullerene guests: $\mathrm{C}_{60}, \mathrm{C}_{70}$, and $\mathrm{C}_{84}$ were considered both experimentally and theoretically; whereas the previously unstudied $C_{76}, C_{78}$, and $C_{90}$ were only considered theoretically. The specially designed monomers 1 composing such host capsules were based on a cyclotriveratrylene (CTV) core, equipped with three 2-ureido-4-[1H]-pyrimidinone (UPy) moieties each bearing an array of two hydrogen bond donors and two acceptors; this enabled facile dimerization into $\mathbf{1}_{2}$ via hydrogen bonding.

The aim of our work, wherein we have observed full agreement between theory and experiment, was to provide an explanation as to why, in previous studies ${ }^{[14-15]}$ such capsules were experimentally seen to prefer $C_{84}$ as a guest over $C_{70}$ and $C_{60}$.

Our ${ }^{1} \mathrm{H}$ NMR findings (1D, NOESY, COSY, HSQC) crucially confirmed that, in THF, the 2-ureido-4-[1H]-pyrimidinone tautomer of UPy was indeed the most prevalent one. In addition, homochiral $\mathbf{1}_{\mathbf{2}}$ capsules-where both monomers $\mathbf{1}$ are of the same chirality $P$ or $M$-were found to prevail over meso capsules—where they have contrasting chirality.

In full accordance with NMR, our calculations further predicted that, regardless of the fullerene guest, and out of seven conformations tested, the capsules' energetically preferred conformation is always $A_{\beta} A_{\beta}$. This entails all UPy urea protons in capsule monomers being oriented anti to CTV methoxy groups (rather than syn), and all CTV-UPy ethylene linkers staying within the plane of the capsule's surface (rather than projecting out).

Again in agreement with previous experimental results for $\mathrm{C}_{60}, \mathrm{C}_{70}$, and $\mathrm{C}_{84}$, we also established that the total encapsulation energy for the six fullerene guests studied follows the trend $C_{60}>C_{70}>C_{76}>C_{78}>C_{84} \approx C_{90}$ (where more negative values correspond to more favorable encapsulation). At first (guests $\mathrm{C}_{60}$ to $\mathrm{C}_{78}$ ), this trend is predominantly driven by increasingly favorable host-guest interactions, arising from an increasing number of tighter host-guest contacts: these are able to overcome the increasing energetic penalties associated with guest-induced distortion and guest-induced disruption of capsules' hydrogen bonds. Eventually, however, these two energetic penalties begin to contrast the beneficial effects of host-guest interactions, and this is at the origin of $\mathrm{C}_{84} @ \mathbf{1}_{\mathbf{2}}$ and $\mathrm{C}_{90} @ \mathbf{1}_{\mathbf{2}}$ having similar formation energies.

Racemization studies, based on CD spectra recorded at different temperatures, were also able to show that with $\mathrm{C}_{84}$ as a guest, disruption of homochiral capsules is less favored than with $\mathrm{C}_{70}$ or $\mathrm{C}_{60}$. This represents another encouraging piece of evidence in favor of our computational findings.

\section{Experimental Section}

Fullerenes and other chemicals were purchased from commercial sources, and used without further purification. Solvents were dried and distilled using conventional methods, ${ }^{[31]}$ or with a Solvent Purification System (SPS). Compound 1 was synthesized as reported elsewhere. ${ }^{[14]}$ NMR spectra were performed on Bruker Advance 400 Ultrashield $\left({ }^{1} \mathrm{H}: 400 \mathrm{MHz},{ }^{13} \mathrm{C}: 100 \mathrm{MHz}\right)$ or 500 Ultrashield $\left({ }^{1} \mathrm{H}: 500 \mathrm{MHz},{ }^{13} \mathrm{C}: 125 \mathrm{MHz}\right)$ spectrometers. Deuterated solvents used are indicated in each case. Chemical shifts $(\delta)$ are expressed in ppm, and are referred to the residual peak of the solvent. High performance liquid chromatography (HPLC) analyses were carried out on an Agilent Technologies Series 1100 apparatus, with UV-diode array detector. HPLC grade solvents were purchased from Scharlab and Carlo Erba and were used with no further purification. Separation of enantiomers was accomplished in a Chiralpak-IC $250 \times 7.8 \mathrm{~mm}, 5 \mu \mathrm{m}$ column from Daicel. The mobile phase was a mixture of DCM/MeOH (90:10 v/v) + 0.1\% TFA, flow rate $=0.95 \mathrm{~mL} / \mathrm{min}$ and detection wavelength $254 \mathrm{~nm}$ at $25^{\circ} \mathrm{C}$. CD measurements were carried out in a Chirascan circular dichroism spectrometer from Applied Photophysics, with simultaneous measurement of UV-vis and CD spectra in the 165 - $900 \mathrm{~nm}$ range. The device was equipped with a Peltier thermal control unit $\left(-40 /+100^{\circ} \mathrm{C}\right)$ with the possibility of temperature ramp control. Experiments were performed using $10^{-4} \mathrm{M}$ solutions of each enantiomer, with HPLC grade chloroform as the solvent. The blank and each of the samples were measured three times using a $0.5 \mathrm{~mm}$ path length light polarized cuvette.

\section{Acknowledgements}

Financial support was provided by Spanish Ministerio de Economia y Competitividad (MINECO, projects CTQ2008-00183, CTQ201129054-C02-02, CTQ2011-28677, and CTQ2014-52824-R), the Generalitat de Catalunya (2009SGR-00259, 2014SGR-00409), the ICIQ foundation, Consolider Igenio 2010 (grant CDS2006-0003), and European FEDER funds, all of which are deeply acknowledged. E. H. also thanks MINECO for a FPI studentship. S. A. S. thanks the Marie Curie/COFUND scheme ref. 291787-ICIQ-IPMP for funding. The Severo Ochoa Excellence Accreditation (SEV-2013-0319) is also gratefully acknowledged.

Keywords: selective purification of fullerenes $\bullet$ supramolecular chemistry $\bullet$ density functional theory $\bullet$ NMR $\bullet$ circular dichroism 
[1] a) T. J. S. Dennis, T. Kai, T. Tomiyama and H. Shinohara, Chem. Commun. 1998, 619-620; b) F. Diederich, R. Ettl, Y. Rubin, R. L. Whetten, R. Beck, M. Álvarez, S. Anz, D. Sensharma, F. Wudl, K. C. Khemani and A. Koch, Science 1991, 252, 548-551; c) F. Diederich, R. L. Whetten, C. Thilgen, R. Ettl, I. Chao and M. M. Álvarez, Science 1991, 254, 1768-1770; d) R. Ettl, I. Chao, F. Diederich and R. L. Whetten, Nature 1991, 353, 149-153; e) A. S. Boutorine, H. Tokuyama, M. Takasugi, H. Isobe, E. Nakamura and C. Helene, Angew. Chem., Int. Ed. 1994, 33, 2462-2465; f) T. Hasobe, H. Imahori, P. V. Kamat, T. K. Ahn, S. K. Kim, D. Kim, A. Fujimoto, T. Hirakawa and S. Fukuzumi, J. Am. Chem. Soc. 2005, 127, 1216-1228; g) G. L. Marcorin, T. Da Ros, S. Castellano, G. Stefancich, I. Bonin, S. Miertus and M. Prato, Org. Lett. 2000, 2, 3955-3958; h) C. M. Sayes, J. D. Fortner, W. Guo, D. Lyon, A. M. Boyd, K. D. Ausman, Y. J. Tao, B. Sitharaman, L. J. Wilson, J. B. Hughes, J. L. West and V. L. Colvin, Nano Lett. 2004, 4, 1881-1887; i) M. Segura, L. Sanchez, J. de Mendoza, N. Martin and D. M. Guldi, J. Am. Chem. Soc. 2003, 125, 15093-15100; j) M. M. Wienk, J. M. Kroon, W. J. H. Verhees, J. Knol, J. C. Hummelen, P. A. van Hal and R. A. J. Janssen, Angew. Chem., Int. Ed. 2003, 42, 3371-3375; k) Y. Yamakoshi, N. Umezawa, A. Ryu, K. Arakane, N. Miyata, Y. Goda, T. Masumizu and T. Nagano, J. Am. Chem. Soc. 2003, 125, 12803-12809.

[2] a) H. Kato, Y. Kanazawa, M. Okumura, A. Taninaka, T. Yokawa and H. Shinohara, J. Am. Chem. Soc. 2003, 125, 4391-4397; b) S. Kobayashi, S. Mori, S. lida, H. Ando, T. Takenobu, Y. Taguchi, A. Fujiwara, A. Taninaka, H. Shinohara and Y. Iwasa, J. Am. Chem. Soc. 2003, 125, 8116-8117; c) M. Saunders, R. J. Cross, H. A. Jimenez-Vazquez, R. Shimshi and A. Khong, Science 1996, 271, 1693-1697; d) M. Saunders, H. A. Jimenez-Vazquez, R. J. Cross, S. Mroczkowski, D. I. Freedberg and F. A. L. Anet, Nature 1994, 367, 256-258.

[3] a) L. Isaacs, A. Wehrsig and F. Diederich, Helv. Chim. Acta 1993, 76, 1231-1250; b) K. C. Khemani, M. Prato and F. Wudl, J. Org. Chem. 1992, 57, 32543256; c) D. H. Parker, K. Chatterjee, P. Wurz, K. R. Lykke, M. J. Pellin and L. M. Stock, Carbon 1992, 30, 1167-1182; d) W. A. Scrivens, P. V. Bedworth and J. M. Tour, J. Am. Chem. Soc. 1992, 114, 7917-7919.

[4] K. Nakamura, T. Sasaki, R. Ogawa and T. Nakai, Jpn. Kokai Tokkyo Koho 1997, JP 09227111 A 19970902.

[5] R. D. Bolskar and J. M. Alford, Chem. Commun. 2003, 1292-1293.

[6] I. Bucsi, R. Aniszfeld, T. Shamma, G. K. S. Prakash and G. A. Olah, Proc. Natl. Acad. Sci. U. S. A. 1994, 91, 9019-9021.

[7] a) T. Andersson, K. Nilsson, M. Sundahl, G. Westman and O. Wennerstrom, J. Chem. Soc., Chem. Commun. 1992, 604-606; b) J. L. Atwood, G. A. Koutsantonis and C. L. Raston, Nature 1994, 368, 229-231; c) T. Suzuki, K. Nakashima and S. Shinkai, Chem. Lett. 1994, 699-702.

[8] a) T. Kawauchi, A. Kitaura, M. Kawauchi, T. Takeichi, J. Kumaki, H. lida and E. Yashima, J. Am. Chem. Soc. 2010, 132, 12191-12193; b) M.-J. Li, C.-H. Huang, C.-C. Lai and S.-H. Chiu, Org. Lett. 2012, 14, 6146-6149.

[9] N. Komatsu, Org. Biomol. Chem. 2003, 1, 204-209.

[10] C. García-Simón, M. Costas and X. Ribas, Chem. Soc. Rev. 2016, 45, 40-62.

[11] T. Haino, C. Fukunaga and Y. Fukazawa, Org. Lett. 2006, 8, 3545-3548.

[12] Y. Shoji, K. Tashiro and T. Aida, J. Am. Chem. Soc. 2004, 126, 6570-6571.

[13] Y. Shoji, K. Tashiro and T. Aida, J. Am. Chem. Soc. 2010, 132, 5928-5929.

[14] E. Huerta, G. A. Metselaar, A. Fragoso, E. Santos, C. Bo and J. de Mendoza, Angew. Chem., Int. Ed. 2007, 46, $202-205$.

[15] E. Huerta, E. Cequier and J. de Mendoza, Chem. Commun. 2007, 5016-5018.

[16] J. W. Steed, P. C. Junk, J. L. Atwood, M. J. Barnes, C. L. Raston and R. S. Burkhalter, J. Am. Chem. Soc. 1994, 116, 10346-10347.

[17] a) B. J. B. Folmer, R. P. Sijbesma, H. Kooijman, A. L. Spek and E. W. Meijer, J. Am. Chem. Soc. 1999, 121, 9001-9007; b) R. P. Sijbesma, F. H. Beijer, L. Brunsveld, B. J. B. Folmer, J. Hirschberg, R. F. M. Lange, J. K. L. Lowe and E. W. Meijer, Science 1997, 278, 1601-1604; c) S. H. M. Söntjens, R. P. Sijbesma, M. H. P. van Genderen and E. W. Meijer, J. Am. Chem. Soc. 2000, 122, 7487-7493; d) F. H. Beijer, H. Kooijman, A. L. Spek, R. P. Sijbesma and E. W. Meijer, Angew. Chem., Int. Ed. 1998, 37, 75-78.

[18] a) S. Grimme, J. Antony, S. Ehrlich and H. Krieg, J. Chem. Phys. 2010, 132, 154104-154122; b) S. Grimme, S. Ehrlich and L. Goerigk, J. Comput. Chem. 2011, 32, 1456-1465; c) E. R. Johnson and A. D. Becke, J. Chem. Phys. 2006, 124, 174104-174112.

[19] F. H. Beijer, R. P. Sijbesma, H. Kooijman, A. L. Spek and E. W. Meijer, J. Am. Chem. Soc. 1998, 120, 6761-6769.

[20] a) J. Canceill, A. Collet, J. Gabard, G. Gottarelli and G. P. Spada, J. Am. Chem. Soc. 1985, 107, 1299-1308; b) J. Canceill, A. Collet and G. Gottarelli, J. Am. Chem. Soc. 1984, 106, 5997-6003; c) A. Collet and G. Gottarelli, J. Am. Chem. Soc. 1981, 103, 204-205; d) A. Collet and J. Jacques, Tetrahedron Lett. 1978, 1265-1268.

[21] Y. Shoji, K. Tashiro and T. Aida, J. Am. Chem. Soc. 2006, 128, 10690-10691.

[22] a) M. Karplus, J. Chem. Phys. 1959, 30, 11-15; b) M. Karplus, J. Am. Chem. Soc. 1963, 85, 2870-2871.

[23] a) G. te Velde, F. M. Bickelhaupt, E. J. Baerends, C. Fonseca Guerra, S. J. A. van Gisbergen, J. G. Snijders and T. Ziegler, J. Comput. Chem. 2001, 22, 931-967; b) C. Fonseca Guerra, J. G. Snijders, G. te Velde and E. J. Baerends, Theor. Chem. Acc. 1998, 99, $391-403$.

[24] http://dx.doi.org/10.19061/iochem-bd-1-7

[25] a) F. Diederich and R. L. Whetten, Acc. Chem. Res. 1992, 25, 119-126; b) R. Taylor, G. J. Langley, A. G. Avent, T. J. S. Dennis, H. W. Kroto and D. R. M. Walton, J. Chem. Soc., Perkin Trans. 2 1993, 1029-1036.

[26] H. Yang, C. M. Beavers, Z. Wang, A. Jiang, Z. Liu, H. Jin, B. Q. Mercado, M. M. Olmstead and A. L. Balch, Angew. Chem., Int. Ed. 2010, 49, 886-890.

[27] a) A. Klamt and G. Schüürmann, J. Chem. Soc. Perkin Trans. 2 1993, 799-805; b) A. Klamt, J. Phys. Chem. 1995, 99, 2224-2235; c) A. Klamt and V. Jonas, J. Chem. Phys. 1996, 105, 9972-9981; d) A. Klamt, V. Jonas, T. Bürger and J. C. W. Lohrenz, J. Phys. Chem. A 1998, 102, $5074-5085$.

[28] As verified by means of structural optimizations on free fullerenes, neither did these suffer any deformation with respect to their structure inside the capsule, nor was their binding energy lowered any further.

[29] a) S. Grimme, Chem. - Eur. J. 2012, 18, 9955-9964; b) J. Antony, R. Sure and S. Grimme, Chem. Commun. 2015, 51, 1764-1774.

[30] A. Collet and J. Gabard, J. Org. Chem. 1980, 45, 5400-5401.

[31] D. D. Perrin, W. L. F. Amarego and D. R. Perrin, Purification of Laboratory Chemicals, $2^{\text {nd }}$ ed., Pergamon Press, Oxford, 1980. 



\section{Entry for the Table of Contents}

Layout 1:

\section{FULL PAPER}

Supramolecular dimeric capsules, based on cyclotriveratrylene equipped with self-complementary ureidopyrimidinone moieties, show selectivity towards $\mathrm{C}_{84}$ and $\mathrm{C}_{70}$ over $\mathrm{C}_{60}$. Combining theory and experiment, we here explore the molecular basis of such selectivity, with fascinating conclusions.

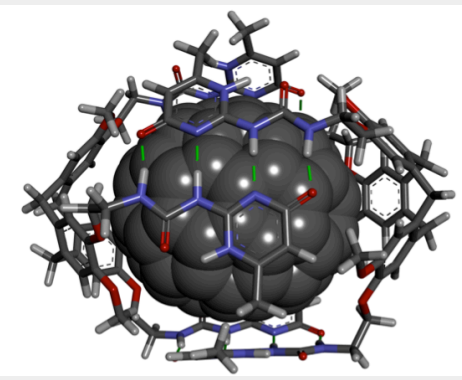

Elisa Huerta, Stefano Artin Serapian, Eva Santos, Enrique Cequier, Carles Bo, ${ }^{*}$ and Javier de Mendoza*

Page No. - Page No.

Molecular basis for the recognition of higher fullerenes into ureidopyrimidinonecyclotriveratrylene self-assembled capsules 